\title{
PREÂMBULO AO ESTUDO DA HISTÓRIA DA ARTE Resenha Crítica
}

Farlley Derze ${ }^{1}$

Brasília, DF, 4 de novembro de 2011

O texto "Preâmbulo ao estudo da história da arte", apresenta uma preocupação voltada ao esclarecimento e entendimento sobre o sentido que determinada realidade cultural faz para os indivíduos que dela fazem parte. É um texto que demonstra cientificidade do pensamento do autor, na medida que promove problematizações. O texto, no que se refere a redação, não cita autores tampouco uma bibliografia, o que suscita a ideia de ser um ensaio que, diante da preocupação em elucidar questões levantadas pelo autor, configura-se também como obra didática. O estilo de redação do autor é conciso, objetivo e coerente, em linguagem culta, e a tradução para a língua portuguesa apresenta palavras comuns ao vocabulário do cotidiano brasileiro que vive no ambiente urbano, da atualidade. O texto possui 30 páginas e se encontra no livro "Guia da história da arte", publicado em Lisboa, Portugal, pela editora Estampa, em 1992, ano de sua primeira edição.

O autor, Giulio Carlo Argan (1909 - 1992) era italiano, formado em Letras. Foi aluno do crítico e historiador da arte Lionello Venturi. Em 1959 sucedeu seu professor Venturi na cátedra de história da arte moderna, na Universidade de Roma. A partir da década de 30 escreveu as seguintes obras:

$\Rightarrow$ L'architettura preromanica e romanica in Italia, 1936;

$\Rightarrow$ L'architettura del Due e del Trecento in Italia, 1937;

$\Rightarrow$ Brunelleschi, 1951;

$\Rightarrow$ Gropius e a Nahaus, 1951, traduzido pela Editorial Presença;

$\Rightarrow$ Beato Angelico, 1955;

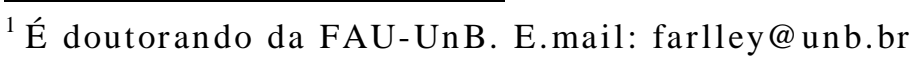


FARLEY DERZE

$\Rightarrow$ Botticelli, 1957.

$\Rightarrow$ E várias monografias e ensaios, como:

$\Rightarrow$ Salvezza e caduta dell'arte moderna, 1964;

$\Rightarrow$ Progetto e destino, 1965

$\Rightarrow$ Occasioni di critica, 1982;

$\Rightarrow$ História da arte como história da cidade, 1983, publicada em português pela Martins Fontes.

$\Rightarrow$ L'arte moderna - Dall'Illuminismo ai movimenti contemporanei, 1988, editado em português pela Companhia das Letras com o título "Arte moderna", em 1992.

Foi prefeito de Roma de 1976 a 1979, e senador em 1983, pelo Partido Comunista Italiano. Seu último trabalho foi "Michelangelo architetto, em 1990. Argan é contemporâneo de Ernest Gombrich e André Chastel. Defendia a tese de que a história da arte era uma história fundamentada nas relações da arte com um sistema produtivo social, de onde se poderia extrair o sentido da arte. Assim, não se contetava com a idéia de a arte se originar a partir de faculdades inatas e descontextualizadas do tempo em que uma obra é produzida.

O autor, primeiramente, apresenta sua preocupação em delimitar o campo da arte, tanto cronologia como geograficamente. Ele considera a arte um fenômeno de difícil delimitação cronológica, mas acredita que se trate daquelas manifestações que ocorreram desde a "mais remota pré-história até os nossos dias atuais" (ARGAN, 1992, p.13). Quanto à delimitação geográfica, o autor acredita que a arte se encontre em "todas as áreas habitadas da comunidade humana, qualquer que seja o seu grau de desenvolvimento cultural” (p. 13). E, sobre o que se poderia considerar uma obra de arte, o autor posiciona-se com um pensamento abrangente, indiscriminatório, onde arte pode ser uma rua, uma moeda, uma ponte, um traje, dentre outros exemplos da produção material forjada pelo homem. Neste sentido, entende que as coisas possuem funções as quais não oferecem critérios para discriminá-las como arte ou não. Deste modo, aquelas coisas poderiam 
possuir funções de caráter prático, representativo ou ornamental, cuja distinção só teria validade "apenas para as culturas que a estabeleceram" (p. 14).

Como consequência deste raciocíno o autor propõe que o conceito de arte não se vincula a uma categoria de coisas, mas a um tipo de valor que seria evidenciável e atribuído à forma visível do objeto. A partir daí, para um objeto ser considerado uma obra de arte, vai depender do julgamento (juízo de valor) que dele se fizer, que nele for atribuído, provavelmente, na medida em que a forma do objeto adquirir, através do gesto mental do observador, o status de significante e consequentemente, dele se colher algum significado. Como a forma, na visão do autor, é algo que se encontra disponível à percepção do indivíduo, o valor artístico de uma forma guarda relação no diálogo que se estabelece pela experiência do indivíduo com o mundo real e a representação do objeto. Para ilustrar minha compreensão deste pensamento de Argan, cito como exemplo a obra "Guernica" (1937), de Pablo Picasso. Imagino que tal obra aos olhos do homem renascentista, por exemplo, não reverberasse com sua experiência de ver em seu cotidiano obras de caráter figurativo, na rotina da linguagem artística daquele período e, ainda, por não reconhecer em sua experiência a que fato ou idéia tal obra se propunha representar. Entretanto, para o homem do século XX, especialmente aquele que tenha conhecimento (experiência) de que tal obra pretendeu representar um evento real, a guerra civil espanhola, seria possível a atribuição de um valor artístico à forma visível, material (significante), disponível à percepção do observador que da obra extrai algum significado. Neste sentido, a história da arte, para Argan, é antes de ser uma história das coisas, uma história de "juízos de valor" (p. 14).

Assim, o entendimento que construí no trilho de raciocínio de Argan me leva a interpretar que fatos de caráter material e inquestionáveis na existência, como a morte ou a guerra, ou fatos ideológicos e culturais a serviço das autoridades do Estado, quando representados sob determinada forma (arquitetura, pintura, escultura, escolas, igrejas, parlamentos, tribunais, etc.), o valor artístico seria gerado por uma atitude política que deriva e se diversifica na esfera social de onde, ou para qual, emerge aquela forma (artística) e o juízo de valor que para ela se decidiu adotar. Tal premissa poderia justificar a importância da história da 
arte como uma história de valores, na história da civilização ocidental.

Para Argan, o valor que a sociedade atribui à arte poderia ser mensurado pela profusão de literatura que dela se ocupa e se ocupou. A literatura sobre arte é categorizada por Argan (p. 14) em quatro eixos, segundo o enfoque dado à arte:

- teoria da arte: explicam e enunciam regras quanto a procedimentos para a prática artística, por exemplo, morfológicas (ordenação, planimetria, etc.), tipológicas (sacra, civil, militar, etc.), estilísticas (simetria, proporção, etc.), técnico-construtiva (os materias a empregar); em alguns casos a teoria da arte pode possuir um caráter dogmático.

- filosofia da arte: discutem e questionam as posssíveis formas de relações que são estabelecidas entre arte, cultura e sociedade.

- história da arte: função de agrupar e ordenar cronologicamente, e geograficamente, "fatos artísticos".

- crítica da arte: propõem discussões sobre a razão da preferência, por exemplo, de se usar determinada cor em detrimento à outra, ou sobre a origem cultural das possíveis reações emocionais que se pode experimentar diante de uma obra. Possuiria uma função política na medida em que manifesta apoio a determinada corrente artística, assim como contém potencial para exercer uma função científica sobre o juízo de valor imputado às obras de arte, por meio da adoção de metodologia baseada em interesses objetivos, pela combinação de dados coletados e analisados em determinda realidade cultural sob uma lógica específica, em detrimento ao subjetivismo do gosto.

O autor acredita que cada ramo da literatura, confome classificação proposta acima, responde aos interesses do período em que foram produzidas. Assim, credita ao séc. XVIII a produção de uma "autêntica" filosofia da arte, na medida em que se valorizam as obras de arte como fatos históricos ligados à história civil e religiosa. Credita ao séc. XVI a "primeira história da arte" expressa pela obra publicada em 1550, do italiano Giorgio Vasari, “Le Vite de' più Eccellenti Pittori, Scultori e Architettori”, que reúne a produção artística de três séculos, de 
Cimabue a Michelângelo. No que se refere à teoria da arte há enfoque diferente, por exemplo, na Idade Média, que possui uma teoria com caráter normativo, dogmático, porque fixava instruções; já no séc. XIV, o "Libro dell'Arte", de Cennini (p. 15) se ocupa em descrever os processos técnicos praticados por Giotto e seus discípulos, portanto, teoria da arte. No caso da literatura voltada à crítica da arte, no séc. XVI promove-se o debate por meio da comparação de obras (p. 15), enquanto no séc. XVII possui caráter parcial com intenção de apoio ou não à produção artística contemporânea, diferentemente da literatura do séc. XVIII onde se desenvolviam fundamentações num esforço filosófico que deixava no centro do debate a questãosobre o juízo de valor atribuído aos objetos, e às ideias. Chega-se ao séc. XIX com a rejeição crescente ao modelo empírico de julgamento e análise, cuja crítica devia apoiar-se em métodos e dados objetivos. Foi assim também com a literatura que se debruçava sobre a história da arte, que deveria se ocupar de localizar, reunir e descrever não apenas as obras (o produto), ou seus autores, mas também a origem das idéias que deram origem à produção da literatura sobre arte.

Argan elucida que o seu "Guia de história da arte" não trata de filosofia da arte, mas apenas da história da arte (p.17). Considera que a obra de arte possui tanto valor histórico quanto os eventos religiosos, políticos e científicos. Como tais eventos podem ser explicados historicamente, a arte também o pode. Isto significa, para ele, que a história da arte possui "a função de estudar a arte não como um reflexo, mas como agente da história" (p. 18).

Tal concepção é problematizada por Argan ao levar-se em conta a seguinte genealogia lógica: a história da arte é a história das obras de arte; mas ocorre que a decisão sobre uma obra ser qualificada como uma obra de arte, surgiria a partir de um juízo crítico em que, devia-se refletir em que consiste tal juízo, suas características e especificidades. Porém, em cada época o juízo foi formulado a partir de parâmetros diversos, tais como: "o belo, a fidelidade na imitação da natureza, a conformidade com certos cânones icónicos ou formais, o significado religioso, o interesse da narração figurativa, etc.” (p. 18). Argan chega a questionar se seria possível haver caráter científico à questão do juízo tendo em vista o juízo variar em cada época, em cada cultura e mesmo para cada pessoa que, ao emití-lo, o faz de maneira diferente da outra. Tal questionamento se faz 
relevante quando se relacionam juízo crítico e valor artístico de uma obra de arte. Para Argan, uma obra seria considerada obra de arte quando tem importância na história da arte, no sentido de haver contribuído na gênese e no percurso de uma cultura artística (p. 19). Consequentemente, ao se fazer um juízo crítico sobre o valor artístico de uma obra não se pode deixar de levar em conta a sua historicidade. Conclusão: a história seria o parâmetro do juízo e fundamentação para a nossa cultura científica.

O valor artístico de uma obra onde a história seria o parâmetro de juízo crítico levou o autor a debater a questão da autenticidade de uma obra como marca de qualidade da mesma. Conceitua autenticidade como "o fato novo desgarrado da tradição". No que tange a questões sobre o estado de conservação de uma obra, é enfático quando diz que uma restauração deveria caber exclusivamente ao historiador de arte (p. 20), na visão dele, única pessoa com perícia suficiente para ajuizar o valor artístico e autenticidade de uma obra de arte e, portanto, a qualidade da mesma. "O conceito de qualidade artística foi definido no século XVIII por. J. Richardson", onde conclui que apenas a crítica poderia descobrir e aferir valor por meio da leitura atenta das obras (p. 21), com menor importância para o que diz o artista e mais importância para como o diz.

“Assim, uma pintura de Ingres não é qualitativamente inferior a uma pintura de Delacroix pelo fato de os contornos serem firmemente marcados e não diluídos, ou as cores cuidadosamente esbatidas e não lançadas à tela com toques rápidos e impetuosos" (p. 22). Detectei nesta lógica de formulação de juízo o problema trazido pelo autor, em páginas anteriores, sobre os critérios que variam no tempo, na cultura e de crítico para crítico. Especificamente, me veio à mente o pintor estadunidense Pollock e seus "toques rápidos e impetuosos".

O autor acredita que a melhor maneira de se exercitar a sensibilidade do historiador de arte se faz por meio da leitura constante do maior número de obras possível. E sua formação se daria de modo mais significativo, ao combinar as leituras com visitas aos museus, às galerias, às igrejas e qualquer lugar onde haja aquilo que se classificou como obras de arte (p. 22).

No tocante aos instrumentos com os quais o historiador vai exercer seu 
trabalho, primeiramente, manter a consciência de que vai lidar com limites dos materiais assim como uma literatura imprecisa como aquelas que circulam pelo mundo em função da prática comercial, além de precisar admitir que existem possibilidades interpretativas sobre a reconstrução da história de uma determinada cultura artística. De todo modo, assim como a literatura e as obras, o historiador pode trabalhar com desenhos existentes em documentos, pesquisas, projetos de preparação de obras e, ainda, réplicas ou cópias que se não são consideradas legítimas não deixam de prestar seu testemunho quando representa um original extraviado. Entretanto, sempre que for possível, o historiador deve recorrer às fontes primárias assim como visitar in loco as obras que pretendeu abordar.

Com este raciocício, Argan apresenta ao interessado na prática de historiador da arte que obras originais existem, entretanto circulam pelo mundo réplicas de obras e desenhos que podem ser de utilidade para se obter referências e que, se for viável, estabelecer contato direto com as fontes originais (obras). Ele acredita que o objetivo do historiador da arte "é explicar a obra de arte como um sistema de relações" possíveis de serem obtidas por meio de uma variedade de confrontos. Tais confrontos serviriam para suscitar analogias temáticas ou formais e suas interdependências de qualidades (características), bem como as divergências, portanto, fazer a junção de diferentes relações. Sobre este último ponto, Argan levanta uma problematização: seria possível que obras produzidas em épocas diferentes pudessem nos levar à conclusão de pertencer a um mesmo artista, sem se recorrer à literatura que comumente classifica obras e estilos?

Eu concluo a partir do texto que a adoção de um comportamento intelectual, por parte do historiador, de modo a ser crítico, problematizador e leitor assíduo de obras, propostas de Argan, favoreceria o historiador da arte a atingir o cerne da questão de seu trabalho: a atribuição, isto é, localizar a obra numa época, sua autoria, sua localização geográfica e o contexto cultural que a gerou, caracterizado pelo conjunto de crenças e valores sociais, além dos materiais que estavam disponíveis em cada época, para cada artista.

Para Argan, lidar com obras do passado não deixa de ser uma atividade de interpretação, e alerta que não cabe dizer que exista interpretação errada ou correta, tendo em vista que as interpretações são diferentes em cada época. Ele 
acredita que "cada cultura é a crítica da cultura precedente" (p. 29) determinada pela situação em que se encontra a cultura do presente. A interpretação resultaria em alguma forma de juízo, de crítica. Tal concepção sintetiza a idéia de se pensar que a história da arte é, na verdade, "a história dos juizos emitidos sobre obras de arte" (p. 30).

Assim, é possível se pensar que a historicidade da arte contém a criticidade. Argan deixa claro seu repúdio à idéia que circulou no passado (preconceito, ele diz) de que ao historiador cabe ocupar-se apenas da "arte antiga", e que o limite de atuação seria o fim do séc. XVIII. O autor não conhece as razões de tal pensamento ter circulado que, por sua vez, imputava ao crítico a tarefa de ocuparse da arte moderna.

Argan não cita autores durante a exposição de suas idéias. Cita, porém, artistas de vários períodos históricos e profissionais ligados à História, Crítica e Filosofia da Arte. Cita-os durante a exposição de uma e outra idéia. O texto não lista, segundo a exigência acadêmica, nenhuma referência bibliográfica.

O texto, em seu formato, está apresentado em 16 seções. A ressalva que faço seria uma alteração na sequência dos capítulos. Eu alocaria o capítulo "Periodização e localização" após o capítulo "Atribuição", tendo em vista que se discute a questão da localização da obra (no tempo, no espaço, nas culturas) em ambos os capítulos, portanto, deviam estar um após o outro em vez de separados por outros capítulos. Eu considero que deviam estar em sequência, em vez de separados, os capítulos "História e crítica", "Método formalista", "Método sociológico", "Método iconológico" e "Método estruturalista", porque apresentam a problematização sobre critérios de investigação e juízo, que atingem diretamente a prática e o raciocínio do historiador da arte.

\section{REFERÊNCIA}

ARGAN, Giulio Carlo; FAgIOLO, Maurizio. Guia de história da arte. Trad.: M. F. Gonçalves de Azevedo. Lisboa: Editorial Estampa, 1992. 